\title{
Justification for Collecting Urgent Care Data to Broaden Syndromic Surveillance
}

\author{
David J. Swenson*2, Em Stephens ${ }^{1}$, Samuel P. Prahlow ${ }^{3}$ and Adejare Atanda ${ }^{4}$
}

1Virginia Department of Health, Richmond, VA, USA; ${ }^{2}$ New Hampshire Department of Health and Human Services, Concord, NH, USA; ${ }^{3}$ Florida Department of Health, Tallahassee, FL, USA; ${ }^{4}$ Maryland Department of Health, Baltimore, MD, USA

\section{Objective}

Provide justification for the collection and reporting of urgent care

(UC) data for public health syndromic surveillance.

\section{Introduction}

While UC does not have a standard definition, it can generally be described as the delivery of ambulatory medical care outside of a hospital emergency department (ED) on a walk-in basis, without a scheduled appointment, available at extended hours, and providing an array of services comparable to typical primary care offices. ${ }^{1} \mathrm{UC}$ facilities represent a growing sector of the United States healthcare industry, doubling in size between 2008 and 2011. ${ }^{1}$ The Urgent Care Association of America (UCAOA) estimates that UC facilities had 160 million patient encounters in 2013. ${ }^{2}$ This compares to 130.4 million patient encounters in EDs in 2013, as reported by the National Hospital Ambulatory Medical Care Survey. ${ }^{3}$ Public Health (PH) is actively working to broaden syndromic surveillance to include urgent care data as more individuals use these services. ${ }^{4} \mathrm{PH}$ needs justification when reaching out to healthcare partners to get buy-in for collecting and reporting UC data.

\section{Keywords}

Urgent Care; Syndromic Surveillance; data collection

\section{Acknowledgments}

Many thanks to all the ISDS CoP jurisdictions and others who shared their UC knowledge and experiences in the February 24th $2017 \mathrm{CoP}$ $\mathrm{UC}$ webinar and Question and Answer session, and to those who have participated in the UC Justification workgroup conference calls. Special thanks go to Rich Thomas, Anna Waller, Serena Rezny, Stacey Hoferka, and Sophia Crossen.

\section{References}

1. Urgent Care Association of America. Industry FAQs. Retrieved from http://bit.ly/2lEZTtK

2. Urgent Care Association of America. (2014). The Urgent Care Association of America Unveils New Accreditation Program. PR Newswire. Retrieved from http://prn.to/2wPcQXh

3. Rui P, Kang K, Albert M. National Hospital Ambulatory Medical Care Survey: 2013 Emergency Department Summary Tables. Retrieved from: http://bit.ly/2yhLgoG

4. Centers for Disease Control and Surveillance. (2015). The National Syndromic Surveillance Program: Enhancing Syndromic Surveillance Capacity and Practice. FOA: CDC-RFA-OE15-1502. Retrieved from http://bit.ly/2yFXwRa

\section{*David J. Swenson}

E-mail: David.Swenson@dhhs.nh.gov 